\title{
Using chlorophyll as gamma absorber
}

\author{
Jaleel Kareem Ahmed \\ Polymer and Petrochemical Industries Department, College of Materials Engineering, Babylon University, Babylon, Iraq
}

\section{Email address:}

jaleel_karim@yahoo.com (J.K._Ahmed)

\section{To cite this article:}

Jaleel Kareem Ahmed. Using Chlorophyll as Gamma Absorber. International Journal of Materials Science and Applications. Special Issue: Steel and Direct Reduced Iron (Sponge Iron) Industry. Vol. 4, No. 2-1, 2015, pp.37-42. doi: 10.11648/j.ijmsa.s.2015040201.17

\begin{abstract}
Chlorophyll extracted from celery using 50\% v/v water - methyl alcohol as a solvent. By this method the concentration of chlorophyll was $22.6 \%$ with yellowish-green color. This solution showed strongly absorption at $400-210 \mathrm{~nm}$ and maximum was at the end of ultra-violet region. This absorption appeared in water, methyl alcohol, and acetone, but strongest absorption was in water. No emission spectra was detected in the ultra-violet and visible regions which means that chlorophyll absorbs radiation and dissipate it as a heat.Several samples of the above solution was radiated by gamma ray from cesium-137 with energy of $0.7 \mathrm{Mev}$ for different intervals $(0.5,1,2,4,24$ hours). The color of the solution disappeared after two hours radiation while the $\mathrm{pH}$ decreases from 6.38 for unradiated to radiated celery solution 4.17 after 24 hours radiation with liberation of carbon dioxide which indicates destroying of chlorophyll but the absorption at $400-210 \mathrm{~nm}$ still exists which reflects the high stability of the group magnesium-four nitrogen atoms (tetrapyrrole) its energy about $3500 \mathrm{~kJ} \mathrm{~mol}^{-1}$. The resulted carbon dioxide carries by hemoglobin to expel via lungs similar to that produces by biological activity of the body.Calculation showed that the dosage of two hours radiation in which color of the solution disappeared (Compton effect) was 5.6 killogray ( 1 gray $=1$ Joule per $1 \mathrm{~kg}$ sample) absorbed by chlorophyll before color disappear is enough to kills 1120 people weight $75 \mathrm{~kg}$ each within 14 days when the whole bodies exposure at one time.The samples glass containers and their white plastic covers of the radiated samples for 4 and 24 hours changed their color to violet may be due to the rearrangement of their physical structures. Others interesting points will appear in the full article.Capsules used as carrier for the chlorophyll to take it by children.
\end{abstract}

Keywords: Chlorophyll, Gamma Ray, pH, Celery, Energy

\section{Introduction}

The traping of light energy is the key to photosynthesis[1,2]. The first event is the chloroplasts of most green plants is the pigment molecule chlorophyll.

Chlorophylls are very effective photoreceptors because they contain networks of conjugated double bonds alternating single and double bonds. Such compounds are called conjugated polyenes. In polyenes, the electrons are not localized to a particular atomic nuclens and consequently can more readily absorb light energy. Chlorophylls have very strong absorption bands in the visible and ultra-violet regions of the spectrum, where the solar output reaching Earth is maximum. Chlorophyll's peak molar extinction coefficient, a measure of a compound's ability to absorb light, is higher than $10^{5} \mathrm{M}^{-1} \mathrm{~cm}^{-1}$, among the highest observed for organic compounds[1].

When light is absorbed by a pigment molecule such as chlorophyll, the energy from the light excites an electron from its ground energy level to an excited energy level. This high energy electron can have one of two fates[3]. For most compounds that absorb light, the electron simply returns to the ground state and the absorbed energy is converted into heat. However, if a suitable electron acceptor is nearby, the excited electron can move from the initial molecule to the acceptor. A positive charge forms on the initial molecules, owing to the loss of an electron, and a negative charge forms on the acceptor, owing to the gain of electron. Hence this process is referred to as photo induced charge separation.

\section{Experimental[4]}

1) Clean celery plant by distill water first then by salty water and finally by water.

2) Extrude clean celery and capsulated.

3) $0.4855 \mathrm{~g}$ celery extruded and dissolved in one liter of $50 \% \mathrm{v} / \mathrm{v}$ water : methyl alcohol solvents using ultrasonic waves with slightly bath heating for 
agitation. Yellowish green solution obtained, as stock solution[5].

4) Magnesium in celery solution determined by induction coupling plasma jy 2000 system with a temperature range $6000-10000{ }^{\circ} \mathrm{C}$.Standard solutions of $1,2,4 \mathrm{ppm}$ magnesium are used for standardization. These solutions are prepared from magnesiummetal in 3\% nitric acid. The result shows the magnesium concentration is $3 \mathrm{ppm}$.

5) Also atomic absorption instrument is used to determine the magnesium concentration. The result shows 3.04 part per million (ppm). See table (1).

Table 1. shows the concentration of magnesium at $285.2 \mathrm{~nm}$.

\begin{tabular}{ll}
\hline Absorptivity & Concentration of $\mathbf{m a g n e s i u m} / \mathbf{p p m}$ \\
\hline 0.252 & 1 \\
0.504 & 2 \\
0.908 & 4 \\
1.469 & 7.2 \\
0.687 & Unknown (3.04) \\
\hline
\end{tabular}

6) Iron in celery solution is determined using atomic absorption instrument (see table 2).
Table 2. shows the concentration of iron at $248.3 \mathrm{~nm}$.

\begin{tabular}{ll}
\hline Absorptivity & Concentration of iron $/ \mathbf{p p m}$ \\
\hline 0.035 & 1 \\
0.074 & 4 \\
0.161 & 10 \\
0.017 & Unknown $(0.5 \mathrm{ppm})$ \\
\hline
\end{tabular}

7) Iron in celery solution was in divalent valency $\mathrm{Fe}^{2+}$ like its valency in hemoglobin.

8) Sample of celery solution exposed to air for long time, no change in the valency of iron observed.

9) Sample of celery solution exposed to ultraviolet light at $210 \mathrm{~nm}$ for long time, no change in the valency of iron observed.

10) Several experiments are performed on absorption and emission of celery solution in the visible and ultraviolet regions in different solvents such as water, acetone, methyl alcohol, $50 \% \mathrm{v} / \mathrm{v}$ water : methyl alcohol. No emission light is observed as shown in figures 1 and 2 respectively.

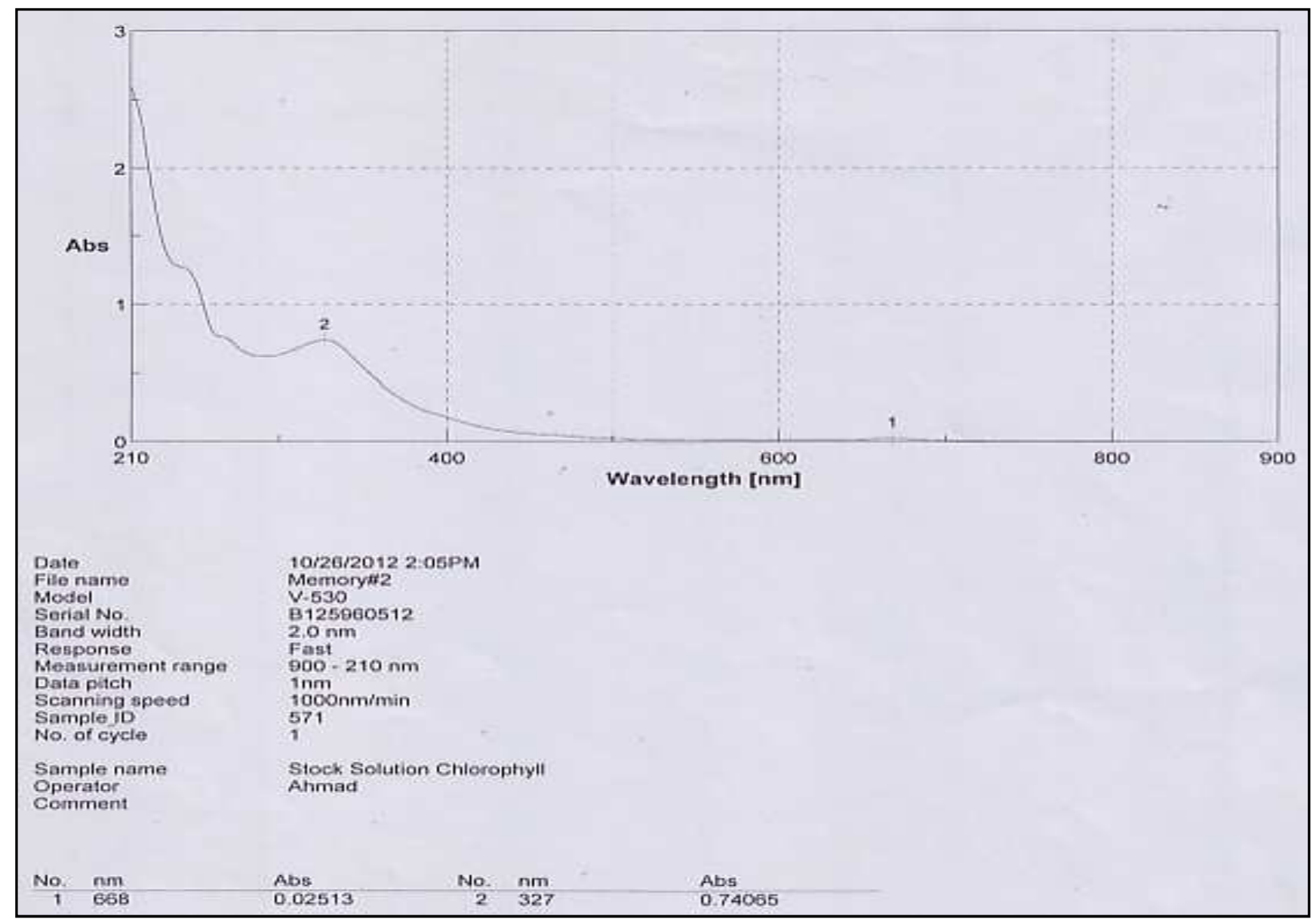

Figure 1. Stock solution chlorophyll. 


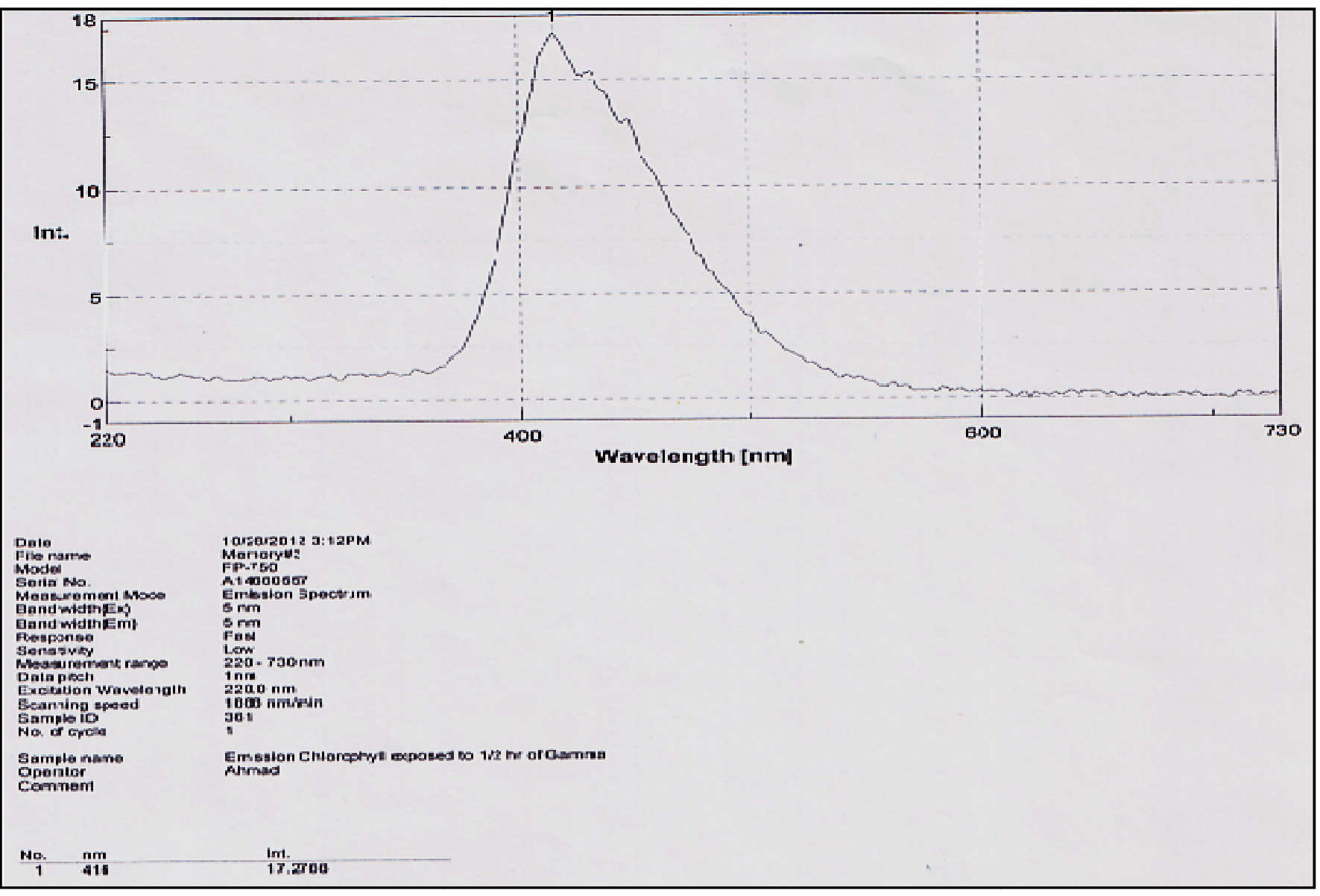

Figure 2. Emission chlorophyll stock solution exposed to 1/2 hr. gamma.

11) The $\mathrm{pH}$ of the solutions used are shown in table 3.

Table 3. The pH of the solutions used.

\begin{tabular}{ll}
\hline Solution & $\mathbf{p H}$ \\
\hline Distilled water & 7.15 \\
$50 \%$ water $+50 \%$ methyl alcohol & 7.85 \\
Celery stock solution & 7.25 \\
\hline
\end{tabular}

12) Two celery stock solutions are radiated by gamma ray from cesium $137(0.7 \mathrm{Mev})$ one for 1/2 hour and the second one for one hour.Their visible - ultraviolet spectra show no change in the shape of the peaks are observed, as well as the color of the solutions not changed.

13) Five sample of celery stock solutions are radiated by gamma ray from the same source in item 12 for $1 / 2,1$, 2, 4, 24 hours. Samples were in glass tube (weight $16.886 \mathrm{~g}$ with the plastic cap) while the weight of the celery solution is $18 \mathrm{~g}$ the capacity of the tube is $18 \mathrm{ml}$.

Box nuclear reactor is used. Radiation was from all directions by rotating the isotopearound the sample. The dosages are shown in table 4. Color of the solution disappeared after two hours.

Table 4. shows the dosages and its time.

\begin{tabular}{ll}
\hline Dosages/(kGray*) & Time/hour \\
\hline 1.6 & 0.5 \\
2.6 & 1.0 \\
$\rightarrow 5.6$ & $2.0 \rightarrow$ color disappeared \\
10.4 & 4.0 \\
62.4 & 24.0 \\
\hline
\end{tabular}

* Gray (Gy) is the metric (SI) measurement unit of absorbed radiation dose of ionizing radiation, e.g. x-rays or gamma ray. The gray is defined as the absorption of one joule of ionizing radiation by one kilogram $(1 \mathrm{~J} / \mathrm{kg})$ of matter, e.g. human tissue.

14) The $\mathrm{PH}$ of theradiated solutions are measured as shown in table 5.

Table 5. shows the $p H$ of theradiated stock solutions.

\begin{tabular}{ll}
\hline Time of radiation $/ \mathbf{h r}$ & $\mathbf{p H}$ \\
\hline Solvent (unradiated) & 7.80 \\
celery solution (unradiated) & 6.38 \\
0.5 radiated & 6.06 \\
1 radiated & 5.88 \\
2radiated & 5.20 \\
4 radiated & 4.55 \\
24radiated & 4.17 with libration of strongly \\
& carbon dioxide \\
\hline
\end{tabular}


15) No effect of gamma radiation on the stability of iron valance $\mathrm{Fe}^{2+}$.

16) No emission of light from radiated solution at ultraviolet or visible regions.

\section{Result and Discussion}

To dissolve chlorophyll from extruded celery used mixed solvents $(50 \% \mathrm{v} / \mathrm{v}$ water $+50 \%$ methyl alcohol) to dissolve chlorophyll and other organic materials by methyl alcohol while inorganic materials such as iron salt dissolves in water. The color of the resulted solution was yellowish-green. This is due to the present of chlorophyll (b) and some of the extruded celery aged ${ }^{[6-10]}$. From the visible - ultraviolet spectra for different celery solutions the order of solubilities were $^{[11]}$ methyl alcohol> acetone $>50 \% \mathrm{v} / \mathrm{v}$ water $+50 \%$ methyl alcohol $>$ water.

Chlorophyll structure consists of tetrapyrrole ring with a central magnesium ion and a long hydrophobic phytol chain. Two types of chlorophyll, (a) and (b) are present in green algae and terrestrial plants. The difference between these two chlorophylls is a methyl moiety in chlorophyll (a) replaced by a formyl group in chlorophyll (b). The ratio of chlorophyll (a) to chlorophyll (b) in higher plants is approximately $3: 1$. Thus there is no significant difference between the two molecular weights (the average molecular weight taken in consideration the ratio $3: 1$ equal to 892.32 $\mathrm{g}$ ), this enhance the idea of determination chlorophyll concentration via determination of magnesium amount in the stock solution using Induction Coupling Plasma and Atomic Absorption Technologies. The results show 3.0 and 3.04 respectively. From the atomic mass of magnesium and the average molecular weight of chlorophyll, the percent of chlorophyll in the stock solution $=\left(892.32 * 3.02 * 10^{-3}\right) /$ $24.3=0.11 \mathrm{~g}$

$$
\text { Chlorophyll \% }=(0.11 / 0.4855) * 100=22.6 \%
$$

From the atomic absorption the concentration of iron is determined. It was $0.5 \mathrm{ppm}$, thus the percent of iron in the celery $=\left[\left(0.5 * 10^{-3}\right) / 0.4855\right] * 100=0.1 \%$

Iron present in celery as ferrous ion $\mathrm{fe}^{2+}$ and do not affected by gamma or ultraviolet radiations or by air, only drops of concentrated nitric acid transfer the ferrous ion to ferric which gives red color with potassium thiocyanate KSCN. Thisreflect the high chemical stability of the ferrous ions in the celery.

A comprehensive study was done on the absorption region with different solvents and for radiated and unradiated samples. All spectra show an absorption starting from $400 \mathrm{~nm}$ and continue out of scale at $210 \mathrm{~nm}$ (see figure1). This reflect the high stability of magnesiumnitrogen structure (tetrapyrrole) in which four nitrogen atoms bonded to the magnesium ion with the theoretical bond energy of $\sim 3500 \mathrm{~kJ} \mathrm{~mol}^{-1}$. Also emission spectra was taken in the ultraviolet region show no significant light emission, this mean that chlorophyll absorbs light and converted to unharmfull heat (see figure 2).

Afive chlorophyll stock solution samples are in glass tubes (capacity $18 \mathrm{ml}$ and its emptyweight with its plastic cap 16.886 gradiated with different time (table 4) and from different angles (box nuclear reactor). The color of solution disappeared after two hours radiation (figure 3) which means that the responsible electrons for the color disappeared this is due to the collision of $\gamma$-ray with these electrons (compton effect). In case of 4 and 24 hours radiation the glass container and their plastic caps change their colors to the violet color. This may be due to the change in their physical structures. Also carbon dioxide liberated from the decomposition of the chlorophyll and this causes decrease in the $\mathrm{pH}$ of the solution up to 4.17 as the radiation time increases (table 5) results from dissolving carbon dioxide in water forming carbonic acid, but the solution still shows absorption of light at the same position $(400-210 \mathrm{~nm})^{4}$ for the unradiated sample, i.e. still the tetrapyrrole ring exist after 0.5 and 24 hours radiation (figures 4 and 5) respectively.

Carbon dioxide results from decomposition of chlorophyll by $\gamma$-ray inside the human body will be treated similar to the carbon dioxide results from the biological activity of human body by carrying it on hemoglobin to expel vialungs.

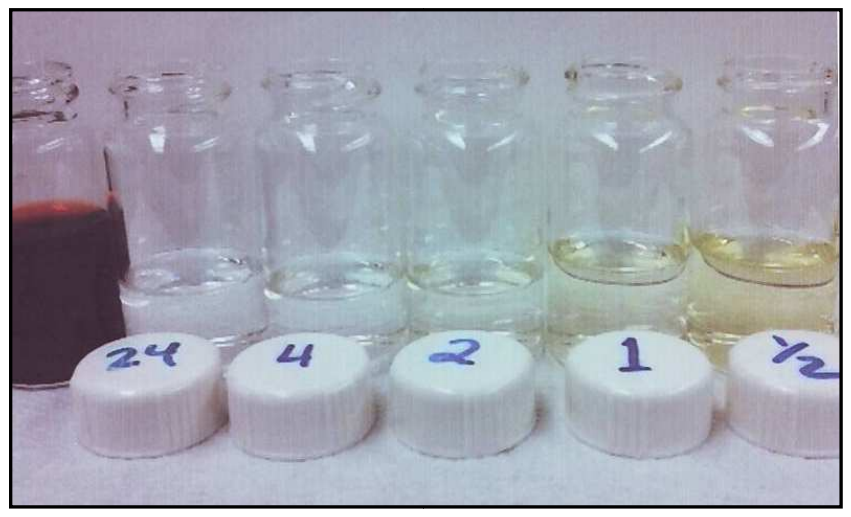

Figure 3. The radiated stock sample with different time.

If whole body exposure to 5 or more gray $[1 \mathrm{Gray}=(\mathrm{J} / \mathrm{kg}$ sample)] of high energy radiation at one time usually lead to death within 14 days. This dosage represents 375 Joules [5( J/kg) $* 75 \mathrm{~kg}$ ] for $75 \mathrm{~kg}$ adult (equivalent to chemical energy in $20 \mathrm{mg}$ of sugar) since gray are such large amounts of radiation, medical use of radiation is typically measured in milligray (mGy), Thus after two hours radiation (Table 4) in which the solution lost its color and starts chlorophyll to decompose, the dosage was $5.6 \mathrm{kGy}$ since 5 Gy killed one adult during two weeks

$$
\therefore 5.6 \mathrm{kGy} \text { killed }\left[\left(5.6 * 10^{3}\right) / 5\right]=1120 \text { Adults }
$$

and the energy absorbed by the chlorophyll sample (16.886 $\mathrm{g}$ the weight of container with its cap $+18 \mathrm{~g}$ weight of the chlorophyll solution)

$$
\text { equal to }=5.6 * 10^{3}(\mathrm{~J} / \mathrm{kg}) * 0.034886 \mathrm{~kg}=195.3 \mathrm{~J}
$$




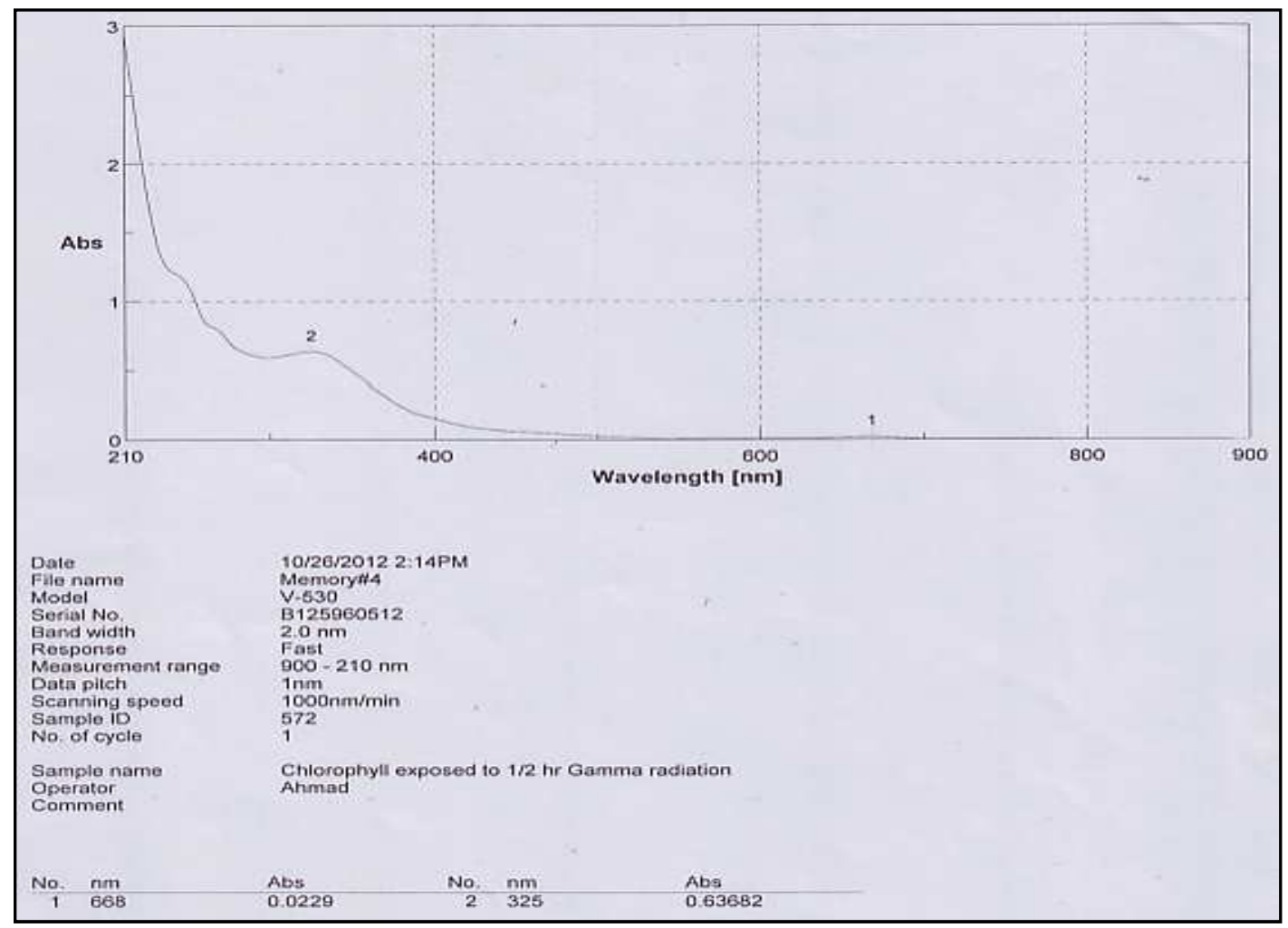

Figure 4. Chorophyllstock solution exposed to $1 / 2 \mathrm{hr}$. gamma radiation.

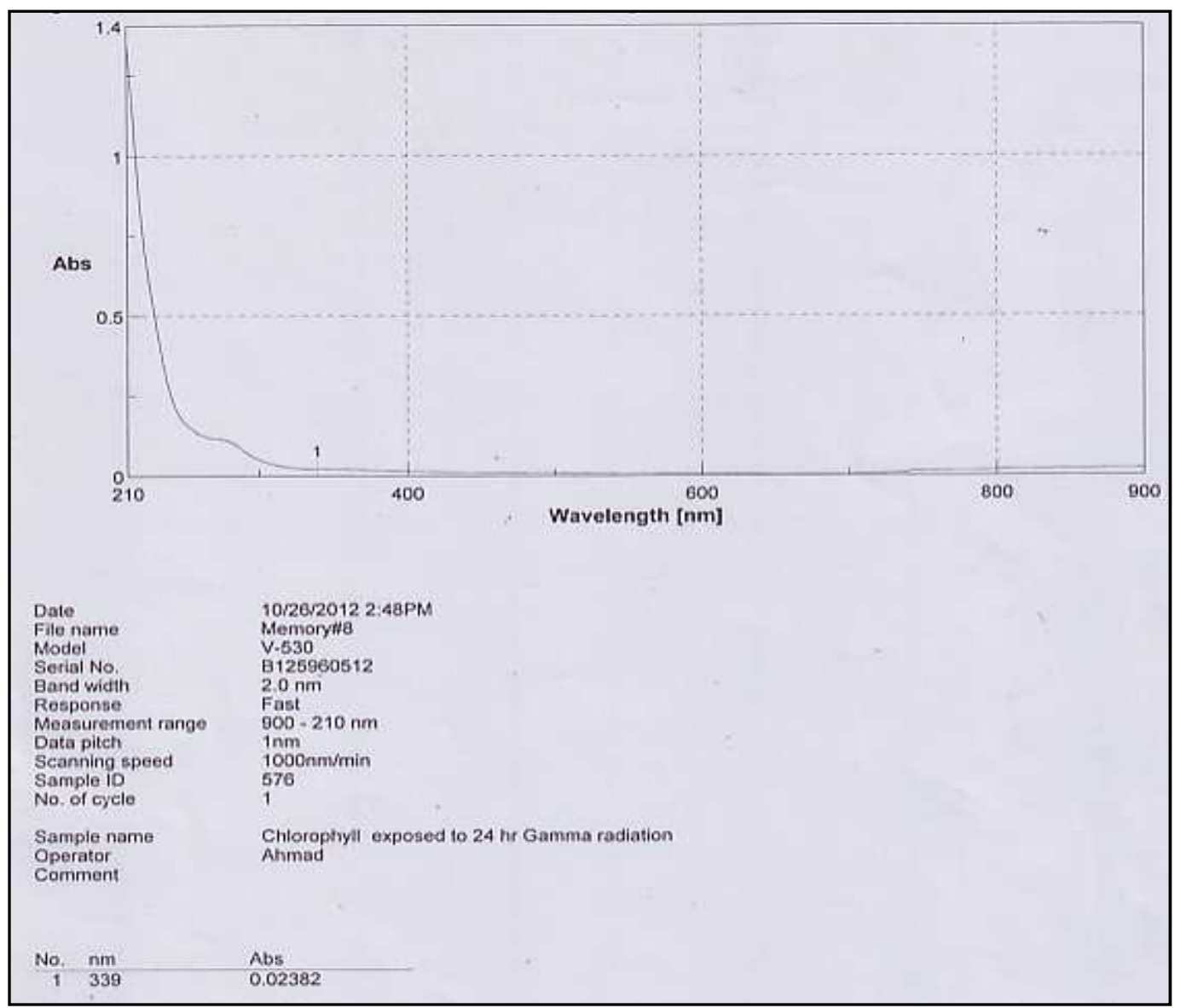

Figure 5. Chorophyllstock solution exposed to $24 \mathrm{hr}$. gamma radiation. 


\section{Acknowledgment}

Thanks to prof. Dr. Goerg Miller and prof. Dr. Ahmed AlShawa from university of California, Irvine, USA for their great helpness to performed this research.

\section{References}

[1] Jeremy M., Berg, John L. Tymoczko, and Lubert Stryer 2012, Biochemistry (7th ed), W.H. freeman and Company.

[2] Photosynthesis Research 76, 227-232, Kluwer Academic publishers, printed in the Netherlands, (2003).

[3] Novoderezhkin ri, Palacios MA, and Van A.H, "Energy Transfer Dynamics in the higher plant", Journal of phy. Vol. 108, pp. 10363 - 10375, (2004).

[4] Al- Asadee Zuhair, " Addition of some Natural Pigments as Colorants and Stabilizer Materials for polymers", Ph. D. thesis,(2007).
[5] Milgrom L., " Chlorophyll is Thicker than Water", Scientist, pp. 12, (1985).

[6] Bailery R., "Green Food in Japan", Nutraceuticalls World, Vol.6, pp. 1807-1812, (2003).

[7] R. L. Pu and p. Gong, Hyperspectral Remote Sensing and its applications , 82, (2000).

[8] Aminol A., and Rey F. Standard Procedure for the determination of chlorophyll by Spectroscopic Methods, March 2000. International council for the Exploration of the Sea , ISSN 0903-2606.

[9] Cwiczenia Z. biochemii. Wydanictwo Naukowe PWN SA Warszawa 1999. ISBN 83-01-13944-7.

[10] Mlodzinska E.(2009). Survey of Plant Pigments: Molecular and Environmental Determinations of plant Colors", Acta Bilogica Cycoviensia Serier Botanica 51/1:7-16.

[11] Lichtenthaler HK, Buschmann C.(2001) Chlorophylls and Carotenoids: Measurement and characterization by UV-VIS Spectroscopy, Current Potocols in Food Analytical Chemistry F 4.3.1-F4.3.8. 